\title{
Aspek Alam sebagai Bagian Therapeutic Architecture pada Rumah Sakit Ketergantungan Obat
}

\author{
Afra Mustika dan Nur Endah Nuffida \\ Jurusan Arsitektur, Fakultas Teknik Sipil dan Perencanaan, Institut Teknologi Sepuluh Nopember (ITS) \\ J1. Arief Rahman Hakim, Surabaya 60111 \\ E-mail: nuffida@arch.its.ac.id
}

\begin{abstract}
Abstrak-Arsitektur adalah produk dari manusia untuk manusia. Sejak jaman dulu kala, meskipun bentuknya masih sederhana (naungan, lindungan, tumpukan batu), manusia tidak dapat dipisahkan darinya. Sedikit banyak arsitektur atau lingkungan binaan berdampak bagi user bangunan dan lingkungan sekitarnya, seperti kutipan dari Winston Churchill "We shape our building, thereafter they shape us". Secara umum, arsitektur sebagai media behaviour modifier diharapkan membawa dampak positif untuk proses kesehatan jiwa bila diterapkan pada bangunan atau lingkungan binaan. Konsep therapeutic architecture dapat diterapkan pada healthcare building ataupun lingkungan binaan yang terdapat aktivitas pengobatan di dalamnya, seperti rumah sakit ataupun pusat rehabilitasi. Dalam konsepnya, aspek-aspek arsitektur dimanipulasi sedemikian rupa untuk mempercepat proses penyembuhan.
\end{abstract}

Kata Kunci-Behaviour modifier, kesehatan jiwa, lingkungan binaan, therapeutic architecture.

\section{PENDAHULUAN}

$\mathrm{K}$ ONSEP therapeutic architecture menunjukkan manipulasi aspek-aspek arsitektur yang membantu mempercepat proses penyembuhan. Aspek-aspek arsitektur yang disebutkan di atas contohnya adalah warna, bentuk, serta cahaya matahari. Menurut Grinde dan Patil, salah satu manipulasi aspek arsitektur yaitu manipulasi ruang menciptakan landasan untuk menghasilkan lingkungan yang membantu mempercepat penyembuhan pasien melalui faktor-faktor alam seperti suara, cahaya, warna, pandangan, dan bahkan aroma [1].

Beberapa penelitian menunjukkan bahwa manusia memiliki hasrat yang mendasar untuk terhubung dengan alam. Penelitian-penelitian tersebut juga menyatakan bahwa integrasi lingkungan alam ke dalam ruang-ruang tempat manusia tinggal dapat meningkatkan penyembuhan dan tentunya membawa dampak positif pada perubahan emosi [1].

Konsep yang telah disebutkan di atas utamanya diterapkan pada healthcare building seperti rumah sakit, klinik, maupun pusat rehabilitasi. Penelitian yang dilakukan Roger Ulrich menyimpulkan bahwa pemulihan pasien setelah operasi hanya mengambil lebih sedikit obat yang disediakan dan menunjukkan hasil kurang negatif pada komplikasi medis sesudahnya pada saat diperiksa oleh perawat, ketika mereka memiliki jendela di kamar mereka yang menghadap alam hijau, dibandingkan dengan pasien di kamar yang sama serta
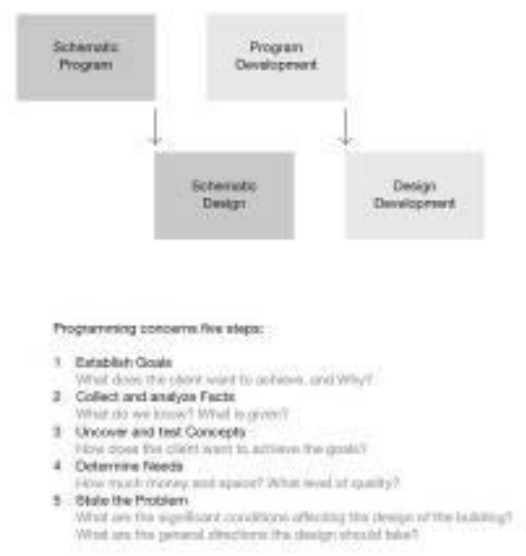

Gambar 1. Langkah-langkah programming dalam perancangan objek arsitektur ini (Sumber How Do You Design? A Compendium of Models: Beta Version)

Penataan massa \& peruntukan ruang sesuai dengan Pedoman Teknis Fasilitas RS Kelas C

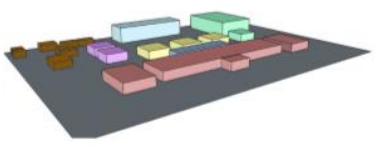

\section{Kamar pasien diletakkan di selatan site agar terhindar dari sinar matahari} yang menyengat

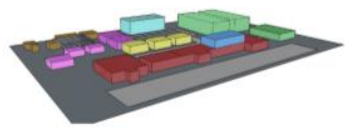

Konteks lingkungan didominasi high rise building, instalasi penunjang medis diletakkan di lantai dasar dengan kamar-kamar di atasnya.

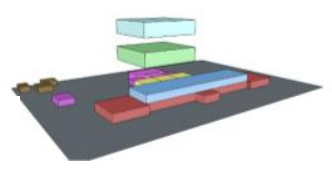

Massa II diperlebar disebabkan kebutuhan ruang IRNA yang bersifat khusus

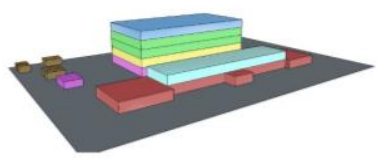

Massa I dibuat melengkung. smooth, memberi kesan "welcome". Massa II pembagian ruang secara blok lurus ke depan tetapi dibentuk sedemikian rupa menyesuaikan bentukan massa

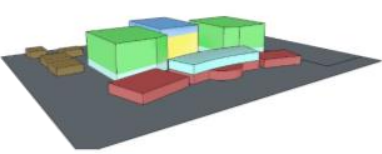

Gambar 2. Eksplorasi bentuk rancangan rumah sakit yang berkonsep therapeutic architecture pada massa bangunannya (Sumber: dok. penulis) 
keadaan yang sama menghadap dinding bata [2], [3]. Penelitian yang lain menunjukkan bahwa tekanan darah tinggi dan aktivitas jantung yang disebabkan oleh stress dapat menurun jika pasien dihadapkan ke pemandangan alam, karena pemandangan tersebut mengalihkan mereka dari pikiran mereka dan masalah yang mengganggu mereka [4]-[6]. Lingkungan alam pada rumah sakit juga dapat memberikan kontribusi untuk integrasi sosial dengan menyediakan ruang untuk interaksi dan dukungan sosial; hal tersebut secara signifikan membantu meningkatkan dukungan sosial bagi pasien, keluarga, dan staff rumah sakit [7].

\section{EKSPLORASI DAN PROSES RANCANG}

Metode yang biasanya digunakan untuk merancang healthcare building khususnya rumah sakit adalah dengan metode programming oleh William M. Pena dan Steven A. Parshall dengan menggunakan pendekatan rasional. Menurut Basics Design Methods oleh Kari Jormakka, pendekatan rasional pada arsitektur membutuhkan adanya pengetahuan dasar di berbagai bidang di luar arsitektur [8]. Dasar yang rasional dan informasi spesifik tersebut kemudian diolah dan menghasilkan berbagai alternatif desain. Sementara programming adalah suatu proses yang mengarah ke statement permasalahan arsitektur dan persyaratan yang harus dipenuhi untuk menawarkan solusi. Pena dan Parshall secara umum menggambarkan pemrograman sebagai pencarian masalah dan desain sebagai pemecahan masalah. Mereka juga menyatakan bahwa programming adalah bagian analisis. Desain adalah bagian sintesis [9].

Untuk desain rumah sakit tentulah diperhatikan bagaimana pemisahan ruang-ruang dan sirkulasi yang terdapat aktivitas yang memicu penularan dan higienitas serta sanitasinya. Desain taman ataupun lansekap pada bagian rumah sakit di mana konsep therapeutic architecture menyediakan space yang berfungsi sebagai tempat yang aman dan meditatif; space tersebut hendaknya recognizeable serta dapat diakses oleh user bangunan tersebut, disamping juga terhindar dari polusi suara (bising) dan polusi udara; space yang terdapat pada taman/lansekap tersebut juga haruslah mampu menampung kegiatan, baik aktif (jalanjalan, exercises) maupun pasif (membaca, berjemur, sightseeing); dan yang paling penting adalah softscape (perdu, rumput, tanaman berbunga, air) yang mendominasi, dipadukan dengan hardscape yang mencakup pathway dan plaza. Hal-hal tersebut di atas menjadi dasar eksplorasi perancangan [10]. Dengan memperhatikan bahwa softscapelah yang mendominasi, perlu juga mencari data mengenai jenis tanaman. Apakah tanaman tersebut termasuk tanaman berbunga aromatis atau tidak, apakah tanaman berbunganya dapat tumbuh di daerah tropis atau tidak, perdu-perdu diletakkan di bagian mana saja; serta aspek teknis seperti bagaimana sistem instalasi air untuk kebutuhan perawatan tanaman dan water feature pada taman yang terletak di dalam gedung, serta kebutuhan cahaya matahari.

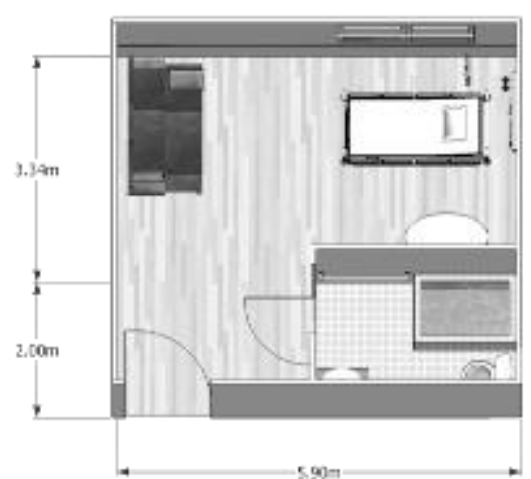

Gambar 3. Modul kamar pasien non infeksius (Sumber: dok. penulis)

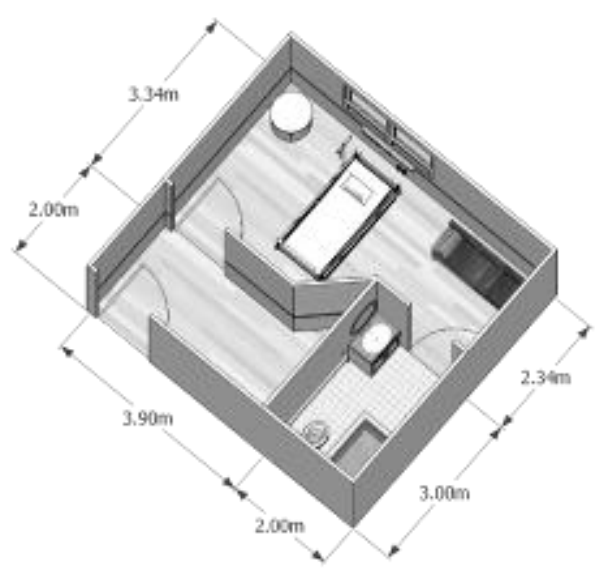

Gambar 4. Modul kamar pasien infeksius (Sumber: dok. penulis)

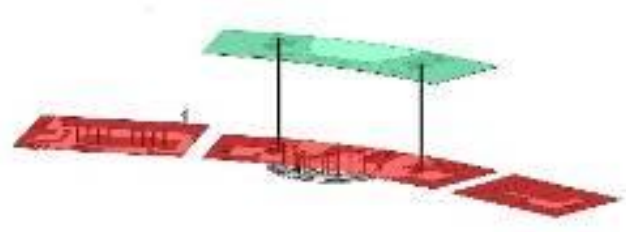

Gambar 5(a). Denah aksonometri massa bangunan melengkung yang menujukkan aspek teknis (sirkulasi) vertikal serta peletakan ruang berkonsep therapeutical architecture (Sumber: dok. penulis)

\section{HASIL RANCANGAN}

Konsep therapeutic architecture dapat diterapkan pada perancangan program ruang, fasad, interior, dan yang terpenting pada lansekap/tamannya. Penerapan konsep therapeutic architecture pada program ruang mengakibatkan munculnya desain kamar inap yang baru, yaitu pemisahan kamar untuk pasien dengan penyakit menular dan penyakit tidak menular. Perbedaan mendasar adalah pada kamar inap pasien dengan penyakit menular, terdapat ruang transisi untuk mencegah penularan langsung. Dengan desain kamar inap yang berbeda berdampak pada desain massa bangunan yang juga memisahkan bagian IRNA dengan kamar inap infeksius dan bagian IRNA dengan kamar inap noninfeksius. Lantai kamar menggunakan lantai parket dengan alasan menghindari adanya nat pada sela-sela lantai rumah sakit pada umumnya serta meningkatkan nilai estetika. 
Lantai parket dipilih warna cerah agar mudah dibersihkan saat diketahui terdapat kotoran yang timbul.

Konsep therapeutic architecture pada fasad lebih difokuskan pada fasad belakang bangunan rumah sakit ini. Fasad belakang lebih ditonjolkan serta diolah karena pada bagian belakang bangunan terlihat jelas indoor garden melalui curtain wall. Indoor wall yang terletak serta terlihat dari belakang menunjukkan bahwa taman tersebut bersifat privat.

Pada interior, konsep tersebut di atas dimunculkan pada ruang rekreasi/ruang berkumpul, ruang duduk, serta tentu saja indoor garden. Pada ruang rekreasi yang berfungsi sebagai tempat berkumpul serta bersantai, terdapat instalasi lampu berbentuk menyerupai batang pohon. Hal ini dimaksudkan untuk memasukkan unsur alam meskipun artifisial. Hal yang sama diterapkan pula pada ruang duduk. Di tengah-tengah ruang rekreasi terdapat air mancur indoor yang dialirkan melalui kaca agar tidak menciprati user yang berada di situ. Pada bagian lain ruang rekreasi, tempat duduk langsung berhadapan dengan curtain wall agar pasien dapat menikmati sinar matahari serta pemandangan luar tanpa perlu repot-repot keluar gedung. Indoor garden yang menjulang sampai pada lantai IRNA paling atas memiliki desain berundak serta banyak tangga selain untuk stimulasi aktivitas yang bersifat aktif, juga memunculkan desain penataan tanaman yang atraktif. Tangga pada indoor garden selain untuk sirkulasi juga dapat digunakan untuk tempat duduk. Jenis tanaman yang dipilih pada indoor garden ini didominasi oleh perdu serta tanaman berbunga aromatis. Hal ini karena perdu tidak membutuhkan tinggi ruang yang berlebihan mengingat desain yang berundak tidak lebih dari 4 meter. Tanaman berbunga aromatis dipilih untuk menciptakan suasana nyaman melalui aromanya. Jenis tanaman berbunga yang dipilih di antaranya adalah kacapiring, mawar, asoka, dan hydrangea.

Pengolahan elemen outdoor/taman "sisa" lahan pada samping bangunan diolah dengan memberikan ketinggian yang berbeda tiap deck-nya. Hal ini bertujuan memberikan kesempatan kepada user untuk menggunakan space yang tersedia untuk berbagai aktivitas baik aktif maupun pasif. Untuk softscape, di beberapa bagian deck diberi tanaman air seperti teratai dan bambu air, dan di sekeliling deck ditanami pepohonan. Penambahan tanaman hijau terdapat juga pada dinding deck yang diberi tanaman rambat.

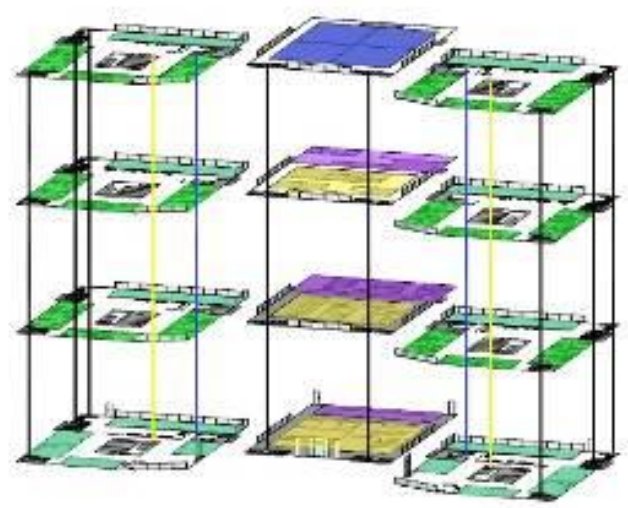

Gambar 5(b). Denah aksonometri massa bangunan di belakang yang menujukkan aspek teknis secara vertikal serta peletakan ruang yang terdapat dalam rumah sakit. Ruang-ruang yang di-highlight warna turqoise menunjukkan ruang-ruang berkonsep therapeutical architecture yang mampu menjadi tempat berlangsungnya pengobatan kesehatan jiwa/rehabilitasi (Sumber: dok. penulis)

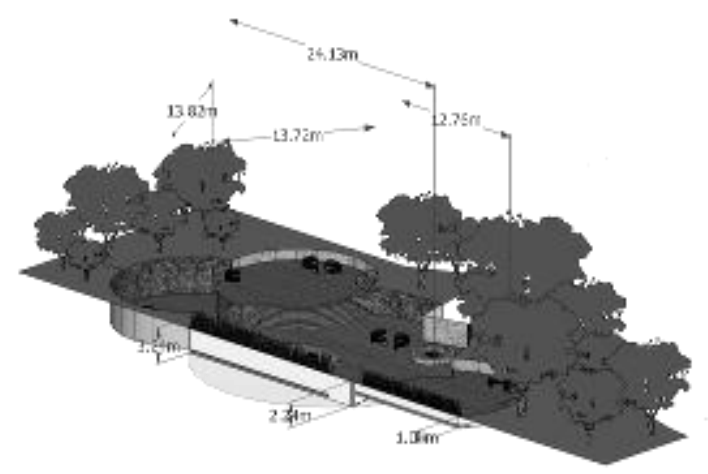

Gambar 6. Desain taman samping bangunan rumah sakit dengan variasi ketinggian serta banyaknya tangga yang menstimulus berbagai kegiatan bersifat aktif (Sumber: dok. penulis)

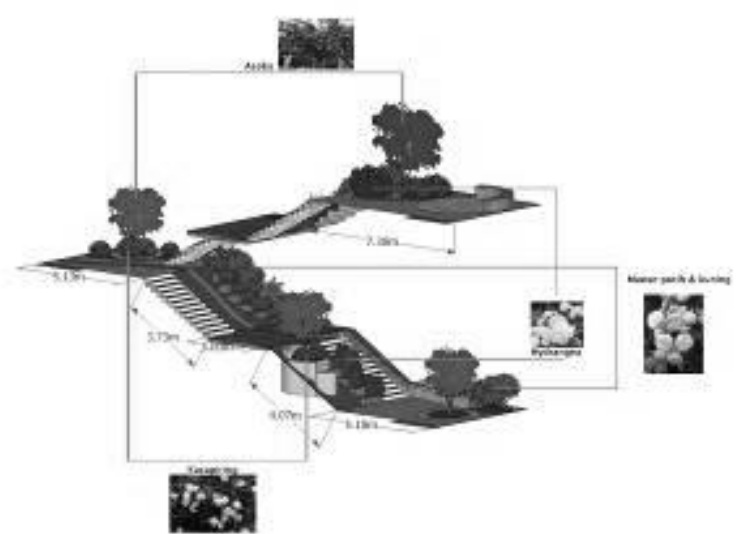

Gambar 7. Desain indoor garden yang menstimulus berbagai indera. Juga ditanam bermacam jenis perdu berbunga aromatis seperti mawar, asoka, kacapiring, dan hydrangea (Sumber: dok. penulis)

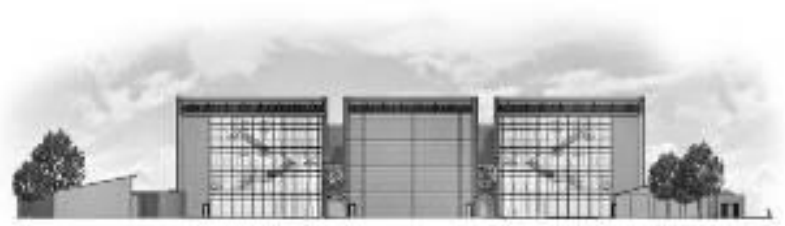

Gambar 8. Tampak pada bangunan rumah sakit yang menunjukkan di dalamnya terdapat indoor garden (Sumber: dok. penulis)

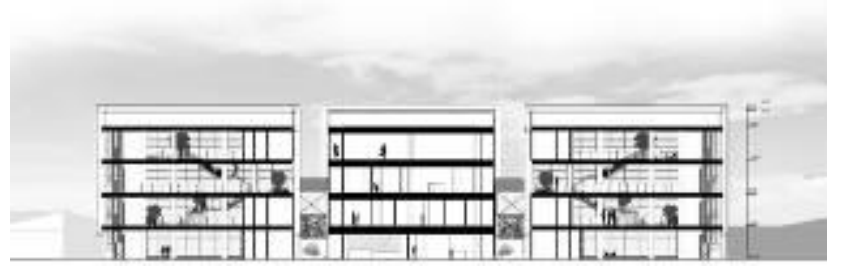

Gambar 9. Potongan massa bangunan rumah sakit yang menunjukkan ruang-ruang serta letak indoor garden (Sumber: dok. penulis) 


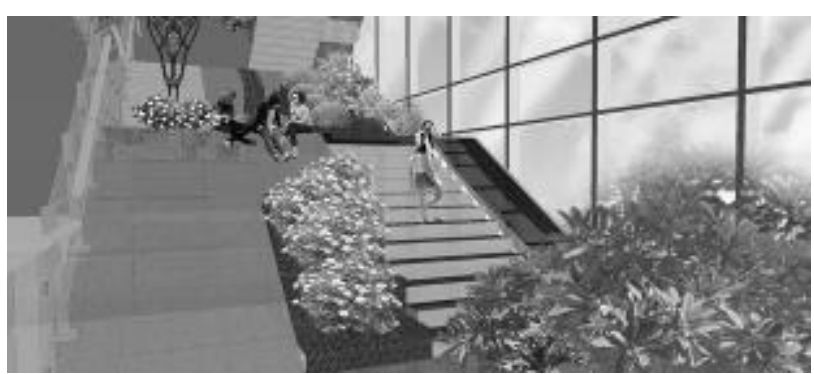

Gambar 10. Ilustrasi indoor garden yang terletak di bagian belakang lantai-lantai IRNA (Sumber: dok. penulis)

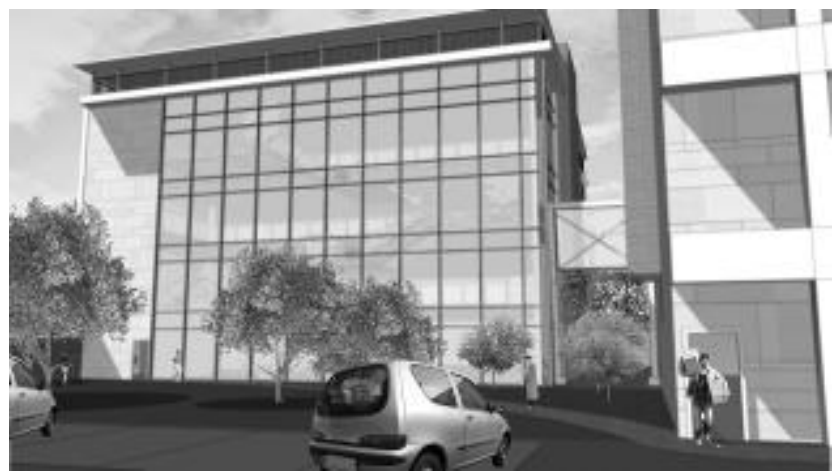

Gambar 11. Ilustrasi fasad bangunan yang menunjukkan adanya indoor garden terlihat melalui curtain wall (Sumber: dok. penulis)

\section{DAFTAR PUSTAKA}

[1] B. Grinde and G. G. Patil. (2009, Aug). Biophilia: Does Visual Contact with Nature Impact on Health and Well-being? Int. J. Environ. Res. Public Health [Mozilla Firefox], 6(9), 2332-2343.

[2] Ulrich, R. S, "View Through a Window May Influence Recovery from Surgery", Science, 1984 Apr 27;224(4647):420-421.

[3] Design of Hospital Gardens Can Promote Health, ProLandscaper Magazine; 2012, July $13 \mathrm{http}: / /$ prolandscapermagazine.com/?p=3166 (diakses Oktober 2016)

[4] C. C. Marcus, Gardens and Health, (IADH) International Academy for Design and Health, (2000).

[5] Whitehouse, S. and Varni, James, W. and Seid, MichaeI and Cooper Marcus, C. and Ensberg, M.J. and Jacobs, J.R. and Mehlenbeck, R.S. (2001, Sept). Evaluating a Children's Hospital Garden Environment: Utilization and Consumer Satisfaction, Journal of Environmental Psychology [Mozilla Firefox]. 21(3). 301-314.

[6] C. C. Marcus and M. Barnes. Healing Gardens: Therapeutic Benefits and Design Recommendations. John Wiley \& Sons. (1999).

[7] C. C. Marcus and M. Barnes. Gardens in Healthcare Facilities: Uses, Therapeutic Benefits, and Design Recommendations. The Center for Health Design, Inc. (1995).

[8] K. Jormakka, Basics Design Method, Birkhäuser Architecture. (2008).

[9] H. Dubberly. How Do You Design? A Compendium of Models (Beta Version). San Francisco: Dubberly Design Office. (2004). halaman 21.

[10] http://www.intechopen.com/books/advances-in-landscapearchitecture/hospital-outdoor-landscape-design (diakses September 2016) 